\title{
EIIIA
}

Revista Eletrônica de Estudos Integrados em Discurso e Argumentação

http://dx.doi.org/10.17648/eidea-13-1370

\section{UM (RE)CORTE DO/NO CORPO: SENTIDOS DE BELEZA E SAÚDE DA CIRURGIA BARIÁTRICA PELO VIÉS MIDIÁTICO}

\author{
Thaís Silva Marinheiro de Paulai \\ Soraya Maria Romano Pacíficoii
}

\begin{abstract}
Resumo: Nesta pesquisa, ao considerarmos que, na contemporaneidade, os discursos circulantes na mídia sobre o corpo belo e perfeito podem afetar a imagem que $o$ sujeito faz de seu corpo, realizamos uma análise de duas capas de revistas, de circulação na sociedade brasileira, que discursivizam a cirurgia bariátrica, buscando interpretar como o discurso midiático constrói e legitima sentidos acerca da obesidade. Além disso, analisamos, também, discursos de sujeitos que fizeram essa cirurgia há mais de um ano, a fim de estabelecer uma comparação entre seus discursos e o discurso midiático, visando interpretar se ambos partilham, ou não, da mesma formação discursiva, isto é, se os sujeitos optam pela cirurgia por uma questão de saúde ou de beleza. Para tanto, os pressupostos teóricos e analíticos utilizados sustentam-se na Análise de Discurso pecheuxtiana. Como resultado, encontramos sentidos dominantes sobre estética e beleza que circulam tanto no discurso midiático, quanto no discurso dos sujeitos-bariátricos.
\end{abstract}

Palavras-chave: Corpo. Discurso. Mídia. Cirurgia Bariátrica.

\begin{abstract}
In this research, when we consider that contemporary circulating discourses in the media about the beautiful and perfect body can affect the image that the subject makes of his body, we perform an analysis of two magazine covers, circulating in Brazilian society, which discursive Bariatric surgery, seeking to interpret how media discourse builds and legitimates meanings about obesity. Besides that, we also analyze the subjects' speeches who underwent this surgery more than a year ago, in order to establish a comparison between their discourses and the media discourse, aiming interpret whether or not they share the same discursive formation, that is, whether subjects choose surgery for a health or beauty issue. For that, the theoretical and analytical assumptions used are based on the pecheuxtiana Discourse Analysis. As a result, we find dominant meanings about aesthetics and beauty that circulate both in the media discourse and in the bariatric subjects' discourse.
\end{abstract}

Keywords: Body. Discourse. Media. Bariatric Surgery.

\footnotetext{
i Mestranda em Psicologia - Faculdade de Filosofia, Ciências e Letras de Ribeirão Preto Universidade de São Paulo (FFCL/RP-USP). E-mail: thaissmarinheiro@gmail.com.

ii Professora Doutora da Faculdade de Filosofia, Ciências e Letras de Ribeirão Preto - Universidade de São Paulo (FFCL/RP-USP). E-mail: smrpacifico@ffclrp.usp.br.
} 
EID\&A - Revista Eletrônica de Estudos Integrados em Discurso e Argumentação, Ilhéus, n. 13, jan/jun.2017.

\section{Introdução}

Ao nos depararmos com os possíveis sentidos que circulam, na contemporaneidade, em relação à obesidade, estética, saúde e preconceito sobre o corpo, podemos dizer que os sujeitos estão expostos a discursos estereotipados pela mídia e pela sociedade que os legitima, de tal forma que a busca por padrões pré-estabelecidos de "corpo ideal" tem se tornado recorrente, no século XXI. Com base nos inúmeros trabalhos acadêmicos que têm surgido (BERG, 2008; OLIVEIRA, 2013) sobre a questão corporal, e na ênfase que a sociedade dá a estereótipos do corpo, realizamos, neste artigo, uma análise de discursos de sujeitos que se submeteram à cirurgia bariátrica há mais de um ano', a fim de interpretarmos os argumentos utilizados pelos sujeitos ao justificarem a escolha pela cirurgia, o que nos permitirá fazer uma comparação com os discursos divulgados pela mídia, acerca do tema obesidade, cirurgia bariátrica, corpo belo. Para atingir esse objetivo, faremos, também, uma análise de duas capas de revistas que tratam sobre o emagrecimento através da cirurgia bariátrica.

A pesquisa é embasada na teoria da Análise de Discurso pecheuxtiana, de modo que para as análises, utilizaremos a noção de recorte que, de acordo com Orlandi (2003, p. 160), é "uma unidade discursiva: fragmento correlacionado de linguagem - e situação", sendo assim, trata-se de um excerto, parte do texto que tem um funcionamento linguístico que pode ser objeto de análise mediante as suas condições de produção.

\section{Um sujeito que se (des)identifica}

Sobre a constituição do sujeito, para a Análise de Discurso de linha francesa, Pêcheux (2009, p. 124) explica que "o indivíduo é interpelado como sujeito [livre] para livremente submeter-se às ordens do Sujeito, para aceitar, portanto [livremente] sua submissão". Nessa mesma perspectiva teórica, Orlandi (2006, p. 19) entende que "a interpelação do indivíduo em sujeito de

\footnotetext{
${ }^{1}$ Para que fosse possível o acesso ao objeto discursivo dessa pesquisa, a construção do corpus passou por algumas etapas, entre elas a submissão do projeto ao Comitê de Ética em Pesquisa da Faculdade de Filosofia, Ciências e Letras de Ribeirão Preto - USP, aprovado e inscrito no número CAAE 45241515.6.0000.5407. O projeto também foi aprovado pela diretoria do Hospital Unimed Bebedouro Cooperativa de Trabalho Médico, tendo em vista que este hospital atuou como coparticipante na pesquisa, pois os sujeitos entrevistados foram escolhidos através do banco de dados do Centro Integrado de Atenção à Saúde (Viver Bem).
} 
EID\&A - Revista Eletrônica de Estudos Integrados em Discurso e Argumentação, Ilhéus, n. 13, jan/jun.2017.

seu discurso se efetua pela identificação do sujeito com a formação discursiva que o domina".

Conforme apontam os autores, compreendemos, então, que não existe um sujeito único, a constituição em sujeito se dá dependendo da condição sócio-histórica em que ele se encontra, juntamente com os discursos que ali circulam, por exemplo, uma mulher pode assumir as posições-sujeito mãe, esposa, trabalhadora e, em outro momento, ao deparar-se com uma revista sobre saúde ou beleza, afetada pelos discursos ali presentes, ela pode assumir a posição-sujeito que se (des)identifica com os sentidos de obesidade ou magreza; com a condição de ser alta ou baixa; de estar dentro ou fora dos padrões de beleza ditados como ideais para determinado momento. Sobre essa desindentificação, Pêcheux (2009, p. 201-202) compreende que ela "constitui um trabalho (transformação-deslocamento) da forma-sujeito e não sua pura e simples anulação"2, ou seja, ao ver uma revista sobre emagrecimento, o sujeito não anula a posição-sujeito mãe para assumir a posição sujeito-obeso ou sujeito-magro. $O$ que acontece é um deslocamento, uma nova identificação, é a filiação a uma outra formação discursiva que a qualquer momento pode retomar a anterior, basta haver a identificação do sujeito com uma dada posição discursiva.

Orlandi (2006, p. 19) explica que "a interpelação do indivíduo em sujeito de seu discurso se efetua pela identificação do sujeito com a formação discursiva que o domina". Assim, o indivíduo se torna sujeito quando deixa indícios em seu discurso de que partilha de uma determinada ideologia, assim como remete Pêcheux (2009, p. 147):

Chamaremos, então, formação discursiva aquilo que, numa formação ideológica dada, isto é, a partir de uma posição dada numa conjuntura dada, determinada pelo estado da luta de classes, determina o que pode e deve ser dito (articulado sob a forma de uma arenga, de um sermão, de um panfleto, de uma exposição, de um programa, etc.).

Ao pensarmos sobre as formações discursivas é importante nos atentarmos ao conceito de discurso, visto que se trata de efeitos de sentidos produzidos entre os locutores (sujeitos-falantes). Isso se dá porque os sujeitos estão afetados pelos sentidos sócio-históricos que perpassam suas memórias discursivas (ORLANDI, 2006). Desta forma, o sujeito é afetado pelas formações discursivas e/ou ideológicas e a subjetividade é marcada em seu

\footnotetext{
${ }^{2}$ Grifos do autor.
} 
EID\&A - Revista Eletrônica de Estudos Integrados em Discurso e Argumentação, Ilhéus, n. 13, jan/jun.2017.

dizer, como traz Coracini (2008, p. 185) ao parafrasear Lacan: "não basta que o outro fale por nós de nós, é preciso que eu fale, que eu escreva, que eu me chame, enfim, que eu construa a 'minha' identidade - que é sempre 'do outro', que vem do outro, já que só me vejo pelo espelho do olhar do outro". Sendo assim, neste trabalho, veremos que o sujeito, muitas vezes, também se vê pelo espelho do olhar da mídia, pois o olhar que a mídia dá ao padrão corporal pode contribuir para que haja uma identificação do sujeito com a formação discursiva que valoriza o corpo magro e "malhado", padrão de beleza, na contemporaneidade. Entendemos, ainda, esse olhar como um exercício de 'poder' argumentativo presente no discurso midiático, isto porque, conforme assevera Pacífico (2002, p. 42):

[...] se argumentar é levar o outro a crer naquilo que se diz, percebemos que a argumentação faz parte da vida do homem e está relacionada à relação de poder que se estabelece, em determinado momento, entre as classes sociais, isto é, sempre haverá quem argumente e quem "é argumentado".

Desta forma, compreendemos que o olhar e a argumentação da mídia contribuem para que o sujeito-leitor e/ou sujeito-obeso identifiquem-se com uma dada formação discursiva, contribuindo para que os sentidos sedimentados sobre corpo magro sejam dominantes, o que se dá porque o discurso midiático funciona como um discurso de poder. Além disso, é importante considerarmos que o corpo é considerado o lugar de inscrição do sujeito, pois é interpretável, assim como afirma Orlandi (2007, p. 12) "os sentidos não são indiferentes à matéria significante".

Entendemos que o corpo também pode ser um lugar de inscrição do sujeito, pois este deixa marcas das inscrições sócio-históricas que o interpelam em seu discurso, como entende Foucault (1979, p.22) ao identificar o corpo como uma "superfície de inscrição dos acontecimentos, [...] lugar de dissolução do Eu". Com Foucault (idem), entendemos que o sujeito tenta se relacionar com o que lhe representa, neste caso, seu corpo. Essa concepção é entendida por Pêcheux (2009) como lugar imaginário do sujeito, ou seja, a imagem que o sujeito faz de si, ou ainda, a imagem que faz de seu corpo dentro de uma determinada condição sócio-histórica.

Essa interpretação permitida pelo corpo possibilita a instituição das relações de poder, tendo em vista que, para Foucault (2012, p. 28), “o corpo é também diretamente mergulhado num campo político; as relações de poder têm alcance imediato sobre ele; elas o investem, o marcam, o dirigem, o 
EID\&A - Revista Eletrônica de Estudos Integrados em Discurso e Argumentação, Ilhéus, n. 13, jan/jun.2017.

supliciam, sujeitam-no a trabalhos, obrigam-no a cerimônias, exigem-lhe sinais". Logo, compreendemos que ao corpo são estabelecidos padrões que configuram o bom andamento do campo político na sociedade; nesse sentido, Marzano-Parisoli (2004, p. 25) compreende que "o corpo sempre foi o reflexo de pressões e de transformações múltiplas fundadas nos valores e crenças promulgados pela sociedade". A autora ainda complementa que

[...] o corpo é o que nos permite encontrar os outros e que manifesta nossa natureza relacional pela afirmação de nossa individualidade. Não obstante, ele também pode, às vezes, ser um obstáculo nas nossas relações intencionais. É por isso que a relação com a corporeidade de cada um pode dar resultados muito diferentes. Podemos ter com o nosso corpo uma relação de dependência e de identificação completa, mas também podemos procurar livrar-nos da materialidade de nosso corpo. (MARZANO-PARISOLI, 2004, p. 14)

Ao tratar sobre a manifestação do corpo e do olhar, é possível constatar o quanto a questão da corporeidade está diretamente ligada à maneira de olhar e ser olhado, isto porque a forma como esse corpo é apresentado, se conforme os padrões estabelecidos, ou não, é que determina essa identificação com o corpo. Esse olhar se torna determinante para a compreensão do corpo no contexto sócio-histórico, pois o corpo em si é opaco, o que o materializa é o olhar dado a ele, seja um olhar de si ou do outro, como aponta Hashiguti (2009, p. 161):

O corpo é, em muitas disciplinas da área da saúde, tomado como biológico, natural, segmentável, controlável e transparente, mas na perspectiva discursiva, ele se desloca para o lugar da opacidade, porque no discurso, ele é forma material que ganha sentido pelo olhar. Um corpo pode ser bonito, feio, obeso, magro, normal, suspeito, exótico, brasileiro ou japonês, por exemplo, a partir do olhar - um olhar entendido não como capacidade de visão - , mas como gesto de interpretação opticamente possível no discurso.

Entendemos, assim, que é através do discurso que o corpo é olhado. Os discursos podem ser construídos, ou não, por sentidos dominantes, que favorecem, mantêm e partilham sentidos sedimentados e parafrásticos, os quais, na maioria das vezes, estimulam e incitam a mudança no/do outro, tudo para que o sujeito que se considera fora dos padrões sociais sinta parte e filie-se às relações de poder e passe a ter/receber um novo olhar, ou ilusão, de inclusão. Essa sensação de inclusão não fica restrita a apenas um grupo, hoje, o preconceito está instalado no feminismo, na homossexualidade, na obesidade, na religião, dentre tantas outras categorias, mas, para este trabalho, analisaremos o corpo em relação à obesidade, em especial, à cirurgia bariátrica. 
EID\&A - Revista Eletrônica de Estudos Integrados em Discurso e Argumentação, Ilhéus, n. 13, jan/jun.2017.

\section{Sujeito e mídia em discurso}

De acordo com o portal ABC da Saúde (https://www.abcdasaude.com.br, último acesso em 15/01/2016) e a SBEM (Sociedade Brasileira de Endocrinologia e Metabologia) (http://www.endocrino.Org.br/o-que-e-obesidade/, último acesso em 15/01/2016), a obesidade é considerada uma enfermidade caracterizada pelo excesso de acúmulo de gordura no corpo. Para a SBEM, o excesso de peso está atrelado a questões genéticas, à má alimentação ou a disfunções endócrinas.

Nessa mesma direção, Puglia (2004, p. 118) aponta que a obesidade "é caracterizada por ser multifatorial, de origem genética e metabólica, agravada pela exposição a fenômenos ambientais, culturais, sociais e econômicos, associados a fatores demográficos (sexo, idade, raça) e ao sedentarismo". Nesse contexto, entendemos que, para o sujeito obeso podem existir distintos e diversos motivos que o tenham levado à obesidade; entretanto, $\mathrm{o}$ fato que destacamos, aqui, são as 'soluções' buscadas como forma de emagrecimento, dentre elas, a cirurgia bariátrica. Para ter acesso a esses sentidos, constituímos um corpus, a partir de um questionário, que foi respondido por cinco homens e nove mulheres, com mais de vinte e cinco anos de idade, que realizaram a cirurgia há mais de um ano. A entrevista foi realizada junto no Hospital Unimed Bebedouro Cooperativa de Trabalho Médico, junto ao Centro Integrado de Atenção à Saúde / Viver. As respostas podem ser observadas nos discursos dos sujeitos ${ }^{3}$, construídos como respostas para a questão 3 , do questionário4:

Recorte (1) Sujeito A: Todas as dietas possíveis. Passei pelo efeito sanfona desde de criança. Tomei todo o tipo de medicação existente.

Recorte (2) Sujeito C: Ginástica, reeducação alimentar e regimes miraculosos.

Recorte (3) Sujeito F: Vários, já tomei vários remédios e dietas milagrosas.

Recorte (4) Sujeito G: Muitos remédios p/ emagrecer.

Recorte (5) Sujeito L: Varios regimes. Remedios para emagrecer.

Recorte (6) Sujeito M: Dieta, remédios, ginásticas, shakes.

Recorte (7) Sujeito N: Todos os possiveis e imaginaveis.

A nosso ver, as escolhas pelo modo de emagrecimento podem ser consideradas polissêmicas. Sobre a polissemia, Orlandi (2002, p. 25-26) explica que "o mesmo objeto é afetado por dois (e pode haver mais) movimentos de sentido. Isto é a polissemia: é a simultaneidade de movimentos distintos de

\footnotetext{
${ }^{3}$ Mantivemos a escrita original dos sujeitos entrevistados.

${ }^{4}$ Antes dessa decisão (a cirurgia bariátrica), qual outro método de emagrecimento você utilizou?
} 
EID\&A - Revista Eletrônica de Estudos Integrados em Discurso e Argumentação, Ilhéus, n. 13, jan/jun.2017.

sentido no mesmo objeto simbólico". O que a autora chama de objeto simbólico entendemos, nesta pesquisa, como o corpo do sujeito, ou seja, o sujeito submete seu corpo a escolhas e sentidos polissêmicos de emagrecimento para atingir um determinado padrão. Isso significa que, independentemente, do processo polissêmico a finalidade desse processo se dá na paráfrase, tendo em vista que tentam chegar ao mesmo fim, ao emagrecimento.

A outra solução encontrada por estes sujeitos entrevistados para o emagrecimento foi a cirurgia bariátrica. Conforme a Sociedade Brasileira de Cirurgia Bariátrica e Metabólica (SBCBM), esse tipo de procedimento é indicado para o tratamento da redução de peso e/ou doenças associadas à obesidade. Rezende (2011) explicita que esse procedimento é indicado e eficiente para a obesidade grau III, também conhecida como obesidade mórbida.

Em atenção aos sentidos que permeiam o discurso do paciente bariátrico, o discurso sobre o corpo é o que incita o desejo pelo procedimento, em situações como sensação de exclusão social, ineficiências nas tentativas de dieta, atividades físicas e medicamentos, como afirmam Segal e Ferdinõ, apud $\operatorname{Berg}$ (2008, p. 27):

[...] os principais objetivos das cirurgias bariátricas são a redução de peso associada à melhora da qualidade de vida (queda no desemprego e na depressão e melhora na interação social e na mobilidade física) e a redução de comorbidades (cardiopulmonares: hipertensão, asma, insuficiência cardíaca e insuficiência respiratória; diabetes; esofagite, problemas ginecológicos como infertilidade, incontinência urinária e risco na gestação e no parto; cirrose e fibrose hepáticas; osteoartrite e tromboembolismo)

Além disso, Oliveira (2013, p. 100) explica em sua pesquisa que a mulher vê a cirurgia bariátrica como uma necessidade, pois esta se torna uma possibilidade de inclusão na sociedade, principalmente, no que se refere a ir a determinados ambientes em que ela se priva de ir por considerar-se sujeitoobeso. Ademais, a decisão por um procedimento cirúrgico perpassa por diversos sentidos dominantes que integram os discursos dos sujeitosbariátricos. Essa afirmação pode ser verificada nas pesquisas já realizadas sobre esse tema, como em Berg (2008) que em seu trabalho visa a relacionar a alimentação e a busca pelo corpo ideal à obesidade a partir da teoria freudiana, enquanto Oliveira (2013) trata sobre a sensação de inclusão social da mulher após a cirurgia bariátrica. 
EID\&A - Revista Eletrônica de Estudos Integrados em Discurso e Argumentação, Ilhéus, n. 13, jan/jun.2017.

Dentro da teoria da Análise de Discurso pecheuxtiana não se pode considerar o discurso como unívoco, fechado e restrito, sendo assim, os discursos produzidos sobre cirurgia bariátrica não ficam 'reservados' à área médica, visto que em outras condições de produção, estes discursos, com outros sentidos, podem circular. Neste trabalho, são esses sentidos que serão analisados: os sentidos dominantes e/ou silenciados que a mídia produz sobre a cirurgia de redução de estômago. Isso porque o discurso dominante sobre corpo, do século XXI, em sua maioria, remete à tecnologia, selfies, beleza e estética, o que faz com que os sentidos sobre emagrecimento, muitas vezes, migrem do campo da saúde para o da estética, contribuindo, desta forma, para a estereotipação do corpo belo/perfeito e para a exclusão do sujeito obeso.

Em se tratando dos discursos midiáticos, é importante considerá-los como parte do campo da sociedade do espetáculo, de forma que ali são formulados sentidos dominantes que passam a ser entendidos como sentidos de verdade nas relações sociais. Em sua teoria, Debord (2003, p. 21-22) explica que:

[...] o espetáculo não é necessariamente um produto do desenvolvimento técnico do ponto de vista do desenvolvimento natural. A sociedade do espetáculo é, pelo contrário, uma formulação que escolhe o seu próprio conteúdo técnico. O espetáculo, considerado sob o aspecto restrito dos <meios de comunicação de massa - sua manifestação superficial mais esmagadora que aparentemente invade a sociedade como simples instrumentação, está longe da neutralidade, é a instrumentação mais conveniente ao seu automovimento total.

Compreendemos, portanto, como aponta o autor, que os meios de comunicação de massa, dentro da sociedade do espetáculo, não produzem discursos neutros, mas sim, discursos que invadem a sociedade de maneira silenciosa e, aos poucos, tornam-se dominantes, colaborando, também, para o deslizamento de sentidos outros.

Conforme os estudos de Payer (2015):

[...] o valor que a sociedade vem atribuindo à mídia - ou o poder de interpelação que a Mídia vem exercendo na sociedade - passa a assegurar-Ihe o papel de Texto fundamental de um novo grande Sujeito, o Mercado, agora em sua nova forma globalizada (PAYER, 2015, p. 16, grifos da autora).

A autora ainda complementa: "a mídia pode ser considerada como o Texto fundamental do Mercado na medida em que se compreende texto como a forma material do discurso" (Ibidem, p. 16, grifos da autora). Com base na autora, interpretamos que a materialização de sentidos da mídia, ou seja, o 
EID\&A - Revista Eletrônica de Estudos Integrados em Discurso e Argumentação, Ilhéus, n. 13, jan/jun.2017.

texto da mídia, não tem apenas a função de levar informação ao sujeito leitor/espectador, mas sim, partilha de um jogo discursivo do mercado, jogo este que pode produzir o convencimento, silenciar sentidos e contribuir para os sentidos dominantes, como vemos em Silverstone (2002, p. 263):

Trata-se tão somente de poder, é claro. O poder que a mídia tem de estabelecer uma agenda. $O$ poder que ela tem de destruir alguém. $O$ poder que tem de influenciar e mudar o processo político [...] O poder de mudar o equilíbrio de forças: entre Estado e cidadão; entre país e país; entre produtor e consumidor [...] Trata-se do poder da mídia de criar e sustentar significados, de persuadir, endossar, reforçar. O poder de minar e reassegurar. Trata-se de alcance. E de representação: a habilidade de apresentar, revelar, explicar; assim como a habilidade de conceder acesso e participação. Trata-se do poder de falar e ser ouvido. Do poder de incitar e guiar reflexão e reflexividade. O poder de contar contos e articular lembranças.

De acordo com o autor, o poder da mídia 'sustenta significados'. Pelo viés da Análise de Discurso, podemos interpretar, então, que, a sustentação de significados pela mídia pode levar o sujeito à cristalização de sentidos, o que contribui para o não acesso a sentidos outros e para a restrição de sentidos da memória discursiva do sujeito, que é entendida por Orlandi (2001, p. 31) como o "saber discursivo que torna possível todo dizer e que retorna sob a forma do pré-construído, o já-dito que está na base do dizível, sustentando cada tomada da palavra". Sobre a estagnação da memória discursiva, Payer (2015, p. 23 e 24) explica que

\begin{abstract}
Levar em conta a memória não significa, entretanto, nos atermos a sentidos do passado. Implica, pelo avesso disso, criar condições para se instaurarem, ou não se impedirem, deslocamentos de sentidos nos discursos já cristalizados, deslocamentos que se dão a partir do que faz sentido para os sujeitos implicados, de acordo com as suas condições de produção. Considerar a memória é assim considerar o lugar do outro.
\end{abstract}

Para melhor compreensão sobre o poder da mídia, vejamos, na Figura 1, o funcionamento discursivo de duas capas de revista que abordam a temática do corpo. 
EID\&A - Revista Eletrônica de Estudos Integrados em Discurso e Argumentação, Ilhéus, n. 13, jan/jun.2017.

Figura 1 - Duas figuras que abordam a temática do corpo

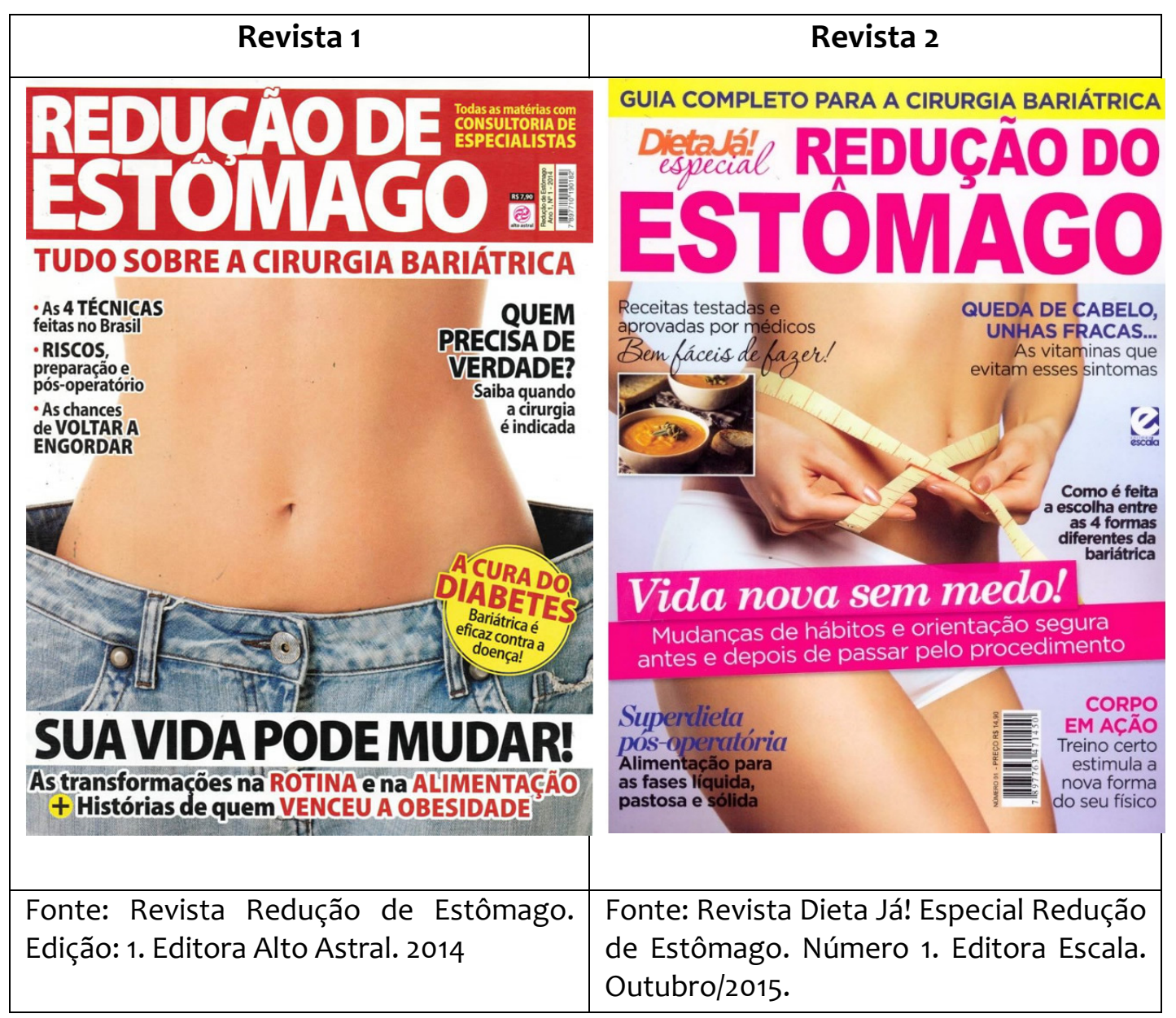

Podemos observar que ambas as revistas tratam sobre cirurgia bariátrica, mas vale salientar que, de acordo com a SBCBM, esse tipo de procedimento é indicado para o tratamento da redução de peso e/ou doenças associadas à obesidade; portanto, segundo o discurso médico, a cirurgia bariátrica não é recomendada para que se atinja o corpo estético, belo, mas sim, o saudável. Desta forma, podemos retornar às revistas e compreender que ambas se utilizam de sentidos sobre saúde, mas as imagens ecoam para imagens de corpos magros conforme estereótipos dos padrões de beleza. Sobre esse eco, Courtine (2013, p. 43) explica que não retomamos apenas dizeres, mas também imagens

[...] a ideia de memória discursiva implica que não existem discursos que não sejam interpretáveis sem referência a uma tal memória, que existe um "sempre já" do discurso, segundo a fórmula que nós empregamos então para designar o interdiscurso. Eu diria a mesma coisa da imagem: toda imagem se inscreve em uma cultura visual, e esta cultura supõe a existência junto ao indivíduo de uma memória 
EID\&A - Revista Eletrônica de Estudos Integrados em Discurso e Argumentação, Ilhéus, n. 13, jan/jun.2017.

visual, de uma memória das imagens onde toda imagem tem um eco. Existe um "sempre já" da imagem. Esta memória das imagens pode ser uma memória das imagens externas, percebidas, mas pode ser igualmente a memória das imagens internas, sugeridas, "despertadas" pela percepção exterior de uma imagem.

De acordo com o autor, 'toda imagem tem um eco', isto é, as imagens (re)produzidas já significaram antes, de modo que elas podem ecoar através de imagens externas ou internas, a primeira de uma maneira mais explícita, enquanto a segunda permanece subentendida. Sendo assim, há um deslize de sentidos na revista, pois é discursivizado sobre saúde, mas as imagens remetem a, ecoam corpos magros, corpos considerados padrões de beleza ou alvos estéticos, na contemporaneidade. Interpretamos, assim, que há um incentivo à cirurgia bariátrica para se chegar a um padrão estético, ao corpo magro e bonito.

Ademais, a Revista 1traz a formulação "Sua vida pode mudar!" e a Revista 2, "Vida nova sem medo!", o que nos leva a interpretar que, para o discurso midiático e/ou de Mercado, a estratégia argumentativa vai na seguinte direção: o emagrecimento constitui o sentido de 'colocar em ordem' a vida do sujeito, reorganizar algo que não segue o padrão, que está 'fora' do lugar; portanto, a obesidade é instituída aqui como um desarranjo social, por isso há tanto estímulo da revista sobre "a nova vida", como se houvesse a necessidade de excluir ou sair da vida obesa. A nosso ver, existe um limite em que a obesidade pode levar o sujeito a sérias comorbidades e estas podem trazer riscos à vida do sujeito. Todavia, nestas capas de revistas não há uma estratégia argumentativa criando sentidos a respeito dos riscos das comorbidades, assim como não são construídos argumentos a partir dos sentidos de saúde para uma nova vida mantendo a estética do 'gordinho', ou como outras mídias apontam para o plus size. A argumentação sustenta-se na estereotipação de sentidos que reiteram que ser saudável é possível, apenas, na medida em que se é magro, como reforçam as imagens das duas revistas.

Essas marcas de incentivo à nova vida 'magra' são ainda fortalecidas pela forma como estão descritos os enunciados "Sua vida pode mudar!" e "Vida nova sem medo!", visto que são graficamente escritas com cores, tamanhos e estilos que destoam do restante dos enunciados, de maneira que apenas 'perdem' destaque para os títulos das revistas. Sobre esse jogo discursivo, Payer (2015, p. 19) explica que "A grandeza da dimensão física dessa linguagem (letras, imagens) parece funcionar como metáfora da dimensão do 
EID\&A - Revista Eletrônica de Estudos Integrados em Discurso e Argumentação, Ilhéus, n. 13, jan/jun.2017.

poder que o Mercado se atribui - e que lhe atribuímos - bem como da dimensão da imagem de grandeza e sucesso projetada sobre os sujeitos".

Além disso, atentemo-nos a outras formulações: na Revista 1, "Tudo sobre a cirurgia bariátrica" e, na Revista 2, "Guia completo para a cirurgia bariátrica". Entendemos que ambas as revistas tentam assegurar ao sujeitoleitor, ilusoriamente, todos os sentidos que circulam sobre cirurgia bariátrica, como se nenhum lhes escapasse, como se fosse possível tudo poder dizer, de modo que o discurso midiático cria o efeito de sentido de discurso verdadeiro que pode contribuir para a decisão do sujeito pelo procedimento cirúrgico. A partir destas formulações entendemos que as palavras 'tudo' e 'completo' funcionam como estratégias argumentativas, pois contribuem para a sedimentação do discurso dominante, na contemporaneidade, que cria a ilusão de que é possível atingir a completude, o todo. Essa estratégia é muito bem empregada pelo discurso midiático, que funciona pela ambivalência, ou seja, oferece tudo para o sujeito consumir, alimentar-se engordar e, em sentido oposto, oferece ao sujeito obeso a ilusão de poder fazer tudo para emagrecer, até a busca pelo procedimento cirúrgico.

Ainda, mediante essas análises, entendemos que a Revista 1, ao dar ênfase à palavra 'Tudo' e ao deixar em destaque a expressão 'sua vida pode mudar' cria o efeito de sentido de incentivo ao procedimento cirúrgico, seja para saúde ou para estética. Assim como a Revista 2, que ao utilizar o termo 'guia' e 'vida nova sem medo' aparenta tratar de um procedimento estabilizado, seguro e bem instruído, o que também indica sentidos favoráveis ao procedimento cirúrgico. Com base no discurso construído nas duas revistas é possível observar a tentativa da mídia de marcar a completude discursiva. Sobre essa completude, Payer (2015, p. 20-21) explicita que:

Quando se trabalha com a linguagem, numa perspectiva como a da Análise de Discurso, aprende-se que tudo não se pode dizer, tudo não se pode saber, tudo não se pode querer. A não ser, vamos acrescentar aqui, ao preço de um esgotamento do simbólico, no ponto em que os sentidos param de funcionar, no estrangulamento das direções e da memória discursivas. Pois se o sujeito se espelha na mídia visualizando outras imagens em si, que passa a perseguir como ideais, este reflexo não deixa de atingir o funcionamento simbólico mais geral no sujeito. Uma das consequências visíveis da obediência cega às leis do mercado é o esgotamento, também, do corpo empírico do sujeito, que se consome em embates simbólicos travados em nome seja apenas de sobreviver nesse contexto, seja do "sucesso" propriamente dito. 
EID\&A - Revista Eletrônica de Estudos Integrados em Discurso e Argumentação, Ilhéus, n. 13, jan/jun.2017.

Por meio dos discursos predominantes nas duas revistas e nas respostas dos pacientes, observaremos se ambos partilham da mesma formação discursiva, o que poderá nos levar a interpretar se a mídia contribui, ou não, para a escolha pelo emagrecimento através da redução de estômago. Sendo assim, os recortes seguintes apresentam discursos de sujeitos que passaram pelo procedimento cirúrgico há mais de um ano, de modo que, como forma de 'amarrar' os sentidos e evitar possíveis deslizes, em cada recorte haverá duas respostas referentes às perguntas $1^{5}$ e $7^{6}$ para que possamos analisar o efeito de sentidos presentes nas respostas. As respostas obtidas foram:

Recorte (8) Sujeito A: Resposta 1: “A certeza (ilusão) de que ficaria magra para sempre, sem sentir fome".

Respsota7: "Ficar magra o mais rápido possível”.

Recorte (9) Sujeito B: Resposta 1: "pressão alta, problemas com coração desgaste, rins pressão alta visão começo de diabete".

Resposta 7: "não ter problema de saúde".

Recorte (10) Sujeito E: Resposta 1: "Estética e saúde".

Resposta 7: "Eram as melhores possíveis, pois eu estava muito feliz apesar das limitações, era o que eu queria para mudar de vida".

Recorte (11) Sujeito F: Resposta 1: "Saúde, dores nas pernas, esporão nos pés dores nas costas, diabete, gastrite, depressão, e muito desânimo".

Resposta 7: "Eu não via a hora de fazer o meu serviço de casa e colocar calça jeans, roupas justas".

Recorte (12) Sujeito J: Resposta 1: "Pelo motivo de impertensão e pré diabétes". Resposta 7: "Perda de peso e alta das medicações que eu tomava para impertenção e pré diabétes".

Recorte (13)Sujeito L: R1: "Problemas de saúde e complexo de obsedade".

R7: "Era para emagrecimento me sentir melhor".

Segundo as argumentações dos sujeitos, compreendemos que há diferentes formações discursivas partilhadas e diferentes posições-sujeito assumidas, isso porque, para o Sujeito A, por exemplo, é assumida a posição sujeito obeso preocupado com a estética, pois ele deixa os termos 'estética' e 'emagrecimento' explícitos em seu discurso, sentidos estes que vão ao encontro da formação discursiva partilhada pela Revista 2, que, mesmo silenciando 'emagrecimento', salienta os sentidos sobre estética. Além disso, o Sujeito A se mantém na mesma formação discursiva em suas respostas, pois os motivos (Questão 1) e a expectativa (Questão 7) para a cirurgia remetem aos mesmos sentidos: estética.

\footnotetext{
${ }^{5}$ Questão 1. Quais os motivos que o (a) levaram a optar pelo procedimento cirúrgico?

${ }^{6}$ Questão 7. Quais eram suas expectativas para o pós-cirúrgico?
} 
EID\&A - Revista Eletrônica de Estudos Integrados em Discurso e Argumentação, Ilhéus, n. 13, jan/jun.2017.

Em contrapartida, o Sujeito B e o sujeito J retomam sentidos sobre saúde, tendo em vista que as duas respostas explicitam a opção pelo procedimento cirúrgico a fim de resolverem problemas como 'pressão alta' e 'diabetes'. Dessa maneira, entendemos que partilham da mesma formação discursiva que a Revista 1, pois esta destaca que a cirurgia bariátrica pode ser eficaz contra o diabetes. Assim, os dois sujeitos, B e J, também partilham da mesma formação discursiva no que dizem respeito aos motivos (Questão 1) e expectativas (Questão 7) quanto ao procedimento cirúrgico: a saúde.

Nos sentidos produzidos pelos Sujeitos E e L, percebemos que não há uma explicitação sobre estética e saúde, mas há indícios que podem ser analisados, como quando o Sujeito E afirma que o motivo (Questão 1) da cirurgia foi por 'estética e saúde', mas ao responder sobre a expectativa (Questão 7) utiliza-se do termo 'limitação' e 'mudar de vida', sentidos que ecoam na estética, assim como os discursivizados pela Revista 1 e pela Revista 2. O mesmo ocorre com o Sujeito L, o seu motivo é apontado por 'problemas de saúde' e, ainda, o 'complexo de obesidade', sentidos que fazem referência aos campos da estética e da saúde; já, na questão sobre a expectativa, o Sujeito $L$ se filia à formação discursiva da estética com os termos 'emagrecimento' e 'me sentir melhor', formações discursivas partilhadas também pelas duas revistas analisadas.

O que chama a atenção nesses dois sujeitos, $E$ e $L$, é que ambos se utilizam do campo da saúde para justificar o procedimento cirúrgico, mas, ao serem questionados sobre a real expectativa, filiam-se mais à formação discursiva da estética do que da saúde, pois entendemos que 'limitação', 'mudar de vida', 'emagrecimento' e 'me sentir melhor' evocam mais sentidos sobre a aceitação e relação com seu próprio corpo do que sobre saúde.

Há, também, o Sujeito $F$ que, ao ser questionado sobre os motivos (Questão 1) que o levaram a optar pela cirurgia bariátrica, marca o interesse por melhora na saúde, ou seja partilha da formação discursiva da saúde, tanto que menciona 'dores nas pernas', 'esporão nos pés', 'dores nas costas', 'diabetes', 'gastrite', ‘depressão' e 'muito desânimo'. Por outro lado, apresenta um deslizamento de sentidos ao ser questionado sobre a expectativa para o póscirúrgico (Questão 7), tendo em vista que retoma sentidos sobre estética ao salientar que 'não via a hora de colocar calça jeans, roupas justas'. Assim, compreendemos que o Sujeito $\mathrm{F}$ deixa silenciado os sentidos sobre estética, mas estes fazem parte de sua expectativa para o emagrecimento. 
EID\&A - Revista Eletrônica de Estudos Integrados em Discurso e Argumentação, Ilhéus, n. 13, jan/jun.2017.

Além disso, observamos, ainda, que o Sujeito $\mathrm{F}$ partilhada da formação discursiva de ambas as revistas. Isso porque o Sujeito $F$ explicita a vontade de usar calça jeans e a calça jeans é um objeto utilizado pela Revista 1, criando a ilusão de que a perda de medidas faz um jeans servir no corpo; o mesmo ocorre com a Revista 2 que apresenta um corpo vestindo uma tanga, esta imagem faz eco no discurso do Sujeito $\mathrm{F}$ quando este faz menção à vontade de usar roupas justas. Neste caso, interpretamos que temos a inculcação do discurso midiático de que a realização da cirurgia bariátrica permitirá que, ao sujeito seja acessível o uso de roupas justas e jeans.

Compreendemos, então, que as revistas tratam sobre os sentidos de saúde, mas, predominantemente, salientam os sentidos de estética, mesmo que isso seja feito de maneira implícita, verbal ou não verbal, com um jogo discursivo de deslizamentos e silenciamentos que nos faz entender que os sujeitos bariátricos assumem as posições mediante os sentidos dominantes que circulam, e, pelo visto, os que mais circulam, mesmo que na tentativa do silenciamento, são os de estética.

\section{Uma conclusão que, obviamente, não diz tudo...}

Com base nas análises, observa-se que a Revista, que faz parte do discurso midiático, reforça, põe em circulação, cristaliza os sentidos dominantes de estética, pois trata o emagrecimento como maneira de se chegar ao corpo e às medidas ideais e não como forma de melhorar a saúde ou a longevidade. Isso permite compreender o quanto a questão corporal se faz presente na contemporaneidade, tendo em vista que o corpo faz parte da representação social, e, cada vez mais, ganha novos olhares: o de si e dos/para os outros. Sobre essa representação social, Courtine (2013, p. 78) entende que "O corpo humano era, e permanece para nós, coberto de signos, mesmo se a natureza destes, o olhar que os decifra, a posição de quem os interpreta e a intenção de quem os exprime se modificarem historicamente", ou seja, podemos entender que o corpo é interpretável, e essa noção de interpretação faz com que o sujeito não queira se sentir excluído, olhado de outra maneira.

Assim, mediante esses discursos midiáticos dominantes, compreendemos que a posição discursiva em que o sujeito-obeso é colocado favorece a exclusão social, de modo que métodos de emagrecimento, como a cirurgia bariátrica, são procurados para que o sujeito consiga, mesmo que ilusoriamente, uma rápida sensação de inclusão social. Nesse sentido, Haroche 
EID\&A - Revista Eletrônica de Estudos Integrados em Discurso e Argumentação, Ilhéus, n. 13, jan/jun.2017.

(2008, p. 157) entende que "As aparências, o mostrar-se e a apresentação de si revelam e também condicionam a inserção do indivíduo nas interações sociais", por conseguinte, como visto, deixar de ser notado pelo seu peso para o sujeito obeso é uma forma de ser inserido na sociedade.

Desse modo, para Foucault (2013, p. 12) "A máscara, a tatuagem, a pintura são operações pelas quais o corpo é arrancado de seu espaço próprio e projetado em um espaço outro", dentro da perspectiva discursiva sobre estética, podemos entender que esta também faz do corpo um espaço outro, pois o corpo obedece a padrões para ser esse outro, caso contrário, esse outro corpo é apagado, não é visto, não recebe o olhar da beleza, olhar este que não é dado à obesidade contribuindo, assim, junto aos discursos da mídia, para sua inferiorização.

Percebemos, portanto, que a cirurgia bariátrica vista tanto nos discursos das revistas quanto pelos sujeitos bariátricos é tomada como forma de estímulo para mudança de vida, mas o que chama a atenção é que para convencer sobre a mudança são apontados alguns sentidos sobre saúde; por outro lado, os que mais fazem parte do convencimento são os sentidos que tratam sobre estética, corpo, físico, sentidos estes que, hoje, fazem parte dos discursos de poder da mídia.

Assim, entendemos que o discurso midiático dominante colabora para o incentivo ao emagrecimento em relação ao corpo obeso, incentivo que estimula a estética corporal e não o corpo saudável, livre de doenças como diabetes, hipertensão e outras. Percebemos ainda que esses mesmos discursos são reproduzidos pelos sujeitos entrevistados, o que nos faz compreender que há uma (pre)dominância da junção emagrecimento e estética dentro dos discursos midiáticos e dos discursos dos sujeitos que realizaram a cirurgia bariátrica. $O$ que nos preocupa nessa relação emagrecimento-estética é que o poder do discurso midiático pode contribuir cada vez mais para a estereotipação dos sentidos que circulam sobre cirurgia bariátrica dentro das formações discursivas sobre estética, enquanto os sentidos sobre saúde ficam silenciados. 
EID\&A - Revista Eletrônica de Estudos Integrados em Discurso e Argumentação, Ilhéus, n. 13, jan/jun.2017.

\section{Referências}

ABC DA SAÚDE. Disponível em: <www.abcdasaude.com.br> Acesso em: 15/01/2016.

BERG, Raquel. Uma análise freudiana da obesidade. Dissertação (Mestrado em Psicologia), Instituto de Psicologia da Universidade de São Paulo, São Paulo, 2008.

CORACINI, Maria José. Escrit(ur)a do corpo no corpo da escrita: da palavra à vidamorte. In: TFOUNI, L. V. Múltiplas faces da autoria. ljuí-RS: Unijuí, 2008. p. 179-197.

COURTINE, Jean-Jacques. Decifrar o corpo: pensar com Foucault. Trad. Francisco Morás. Petrópolis: Vozes, 2013.

DEBORD, Guy. A sociedade do espetáculo: Guy Debord. Projeto Periferia, 2003.

FOUCAULT, Michel. Microfísica do poder. Rio de Janeiro: Graal, 1979.

- Os corpos dóceis. In: . Vigiar e punir: nascimento da prisão. 29.ed. Trad. Raquel Ramalhete. Petrópolis: Vozes, 2012. p. 125-152.

- O corpo utópico, as heterotopias: Posfácio de Daniel Defert. Tradu. Salma Tannus Muchail. São Paulo: n-1 Edições, 2013.

HAROCHE, Claudine A condição sensível: formas e maneiras de sentir no Ocidente. Trad. Jacy Seixas e Vera Avellar Ribeiro. Rio de Janeiro: Contracapa, 2008.

HASHIGUTI, Simone. O corpo como materialidade do/no discurso. In: INDURSKY, F.; FERREIRA, M. C. L.; MITTMANN, S. (Org.). O Discurso na Contemporaneidade: Materialidades e Fronteiras. São Carlos: Claraluz, 2009. p. 161-168.

MARZANO-PARISOLI, Maria Michela. Pensar o corpo. Trad. Lúcia M. Endlich Orth. Petrópolis: Vozes, 2004.

OLIVEIRA, Deise. $O$ processo de tomada de decisão da mulher obesa pela cirurgia bariátrica: uma abordagem compreensiva. 125.f. Tese (Doutorado em Enfermagem). Universidade de São Paulo, São Paulo, 2013.

ORLANDI, Eni. Análise De Discurso: Princípios e Procedimentos. 3.ed. Campinas: Pontes, 2001.

. Língua e conhecimento linguístico: para uma história das idéias no Brasil. São Paulo: Cortez, 2002.

. A linguagem e seu funcionamento: as formas do discurso. 4.ed. Campinas: Pontes, 2003.

- Introdução. In: RODRIGUES, S. L.; ORLANDI, E. P. (Org.) Introdução às Ciências da Linguagem - Discurso e Textualidade. Campinas: Pontes Editores, 2006. 
EID\&A - Revista Eletrônica de Estudos Integrados em Discurso e Argumentação, Ilhéus, n. 13, jan/jun.2017.

- Interpretação: autoria, leitura e efeitos do trabalho simbólico. 5.ed. Campinas: Pontes Editores, 2007.

PACÍFICO, Soraya Maria Romano. Argumentação e autoria: o silenciamento do dizer. Tese (Doutorado), Universidade de São Paulo, Ribeirão Preto, 2002.

PAYER, Maria Onice. Linguagem e sociedade contemporânea - sujeito, mídia, mercado. RUA, Campinas, v. 11, n. 1, p. 9-25, out. 2015.

PÊCHEUX, Michel. Semântica e discurso: uma crítica à afirmação do óbvio. Trad. Eni P. Orlandi. 4.ed. Campinas: Ed.UNICAMP, 2009.

PUGLIA, Carlos. Indicações para o tratamento operatório da obesidade mórbida. Revista da Associação Médica Brasileira, v.50, n.2, p. 118-118, 2004.

REVISTA DIETA JÁ! ESPECIAL REDUÇÃO DE ESTÔMAGO. Disponível em: $\langle w w w . e s c a l a . c o m . b r / d i e t a-j a--e s p e c i a l-r e d u c a o-d o-e s t o m a g o-/ p>$ Acesso em: 06/12/2015.

REVISTA REDUÇÃO DE ESTÔMAGO. Disponível em: <http://www.drandreeyler. com/\#!Saiba-tudo-Sobre-Cirurgia-Bariátrica/c1mbt/55efb7abocf29a3653c4d7b1>. Acesso em: 06/12/2015.

REZENDE, Fabiana. Percepção da imagem corporal, resiliência e estratégias de coping em pacientes submetidos à cirurgia bariátrica. Tese (Doutorado), Universidade de São Paulo, 2011.

SILVERSTONE, Roger. Por que estudar a mídia? São Paulo: Edições Loyola, 2002.

SOCIEDADE BRASILEIRA DE CIRURGIA BARIÁTRICA E METABÓLICA. Disponível em: $<$ www.sbcb.Org.br > Acesso em: 16/01/2016

SOCIEDADE BRASILEIRA DE ENDOCRINOLOGIA E METABOLOGIA. Disponível em: $<W w w . e n d o c r i n o . O r g . b r / o-q u e-e-o b e s i d a d e>$ Acesso em: 15/01/2016.

Forma de citação sugerida:

MARINHEIRO DE PAULA, Thaís Silva; PACÍFICO, Soraya Maria Romano. Um (re)corte do/no corpo: sentidos de beleza e saúde da cirurgia bariátrica pelo viés midiático. EID\&A - Revista Eletrônica de Estudos Integrados em Discurso e Argumentação, Ilhéus, n. 13, p. 191-208, jan/jun.2017.

Recebido em: 05/03/2017

Aprovado em: 04/05/2017 